\title{
Trematode Metacercariae in Freshwater Fish from Water Systems of Hantangang and Imjingang in Republic of Korea
}

\author{
Woon-Mok Sohn",*, Byoung-Kuk Na', Shin-Hyeong Cho², Soon-Won Lee ${ }^{3}$, Seung-Bong Choi', Won-Seok Seok \\ ${ }^{1}$ Department of Parasitology and Tropical Medicine, and Institute of Health Sciences, Gyeongsang National University School of Medicine, \\ Jinju 660-751, Korea; '2Division of Malaria and Parasitic Diseases, National Institute of Health, Centers for Disease Control and Prevention, \\ Osong 363-951, Korea; ${ }^{3}$ Infection Disease Intelligence Division, Gangwon Institute of Health and Environment, Chuncheon 200-822, Korea
}

\begin{abstract}
The infection status of freshwater fish with digenetic trematode metacercariae was examined in water systems of Hantangang and Imjingang (River), the Republic of Korea. A total of 877 (594 from Hantangang and 283 from Imjingang) fishes were examined by the artificial digestion methods. Clonorchis sinensis metacercariae were detected in 7 (1.2\%) fishes (in 3 spp.) from Hantangang in Cheorwon-gun, Gangwon-do, and 40 (14.1\%) fishes (in 7 spp.) from Munsancheon in Paju-si, Gyeonggi-do. The average densities were 1.9 and 35.6 per fish infected, respectively. Metagonimus spp. metacercariae were detected in 312 (52.5\%) and 113 (39.9\%) fishes from Hantangang and Imjingang, and their average densities were 47.5 and 9.6 per fish infected, respectively. Centrocestus armatus metacercariae were found in 161 (27.1\%) and 70 (24.7\%) fishes from Hantangang and Imjingang, and their average number per fish infected was 694 and 82, respectively. Echinostoma spp. metacercariae were detected in 50 (8.4\%) and 94 (33.2\%) fishes from Hantangang and Imjingang, and their average densities were 9.6 and 23.1 per fish infected, respectively. The infection status of fishes with metacercariae of Stephanoprora spp., Diplostomum spp., Clinostomum complanatum, Metorchis orientalis, and Metorchis taiwanensis were analyzed by surveyed regions. Conclusively, it was confirmed that $C$. sinensis metacercariae were quite commonly detected in fishes from Munsancheon but rarely from other localities, whereas the metacercariae of other digenetic trematodes were relatively prevalent in fishes from water systems of Hantangang and Imjingang in Korea.
\end{abstract}

Key words: Clonorchis sinensis, Metagonimus spp., Centrocestus armatus, Echinostoma spp. and Stephanoprora spp., Diplostomum spp., freshwater fish, digenetic trematode, metacercaria, Hantangang, Imjingang

\section{INTRODUCTION}

Digenetic trematodes (subclass Digenea) are a relatively large group comprising of more than 2,500 nominal genera, and generally has 3 hosts, 2 intermediate and 1 definitive, in the life cycle. A variety of vertebrates, i.e., fish, amphibian, reptilian, and arthropod, act as the second intermediate hosts containing the infective larvae, metacercariae. Most of digenetic trematode metacercariae (DTM) are detected in the fish hosts, and are morphologically distinguished because they retain unique morphologies species by species $[1,2]$. In the Republic of Korea (Korea), since Chun [3] reported various DTM

\footnotetext{
- Received 1 March 2015, revised 12 May 2015, accepted 13 May 2015.

*Corresponding author (wmsohn@gnu.ac.kr)

(C) 2015, Korean Society for Parasitology and Tropical Medicine

This is an Open Access article distributed under the terms of the Creative Commons

Attribution Non-Commercial License (http://creativecommons.org/licenses/by-nc/3.0)

which permits unrestricted non-commercial use, distribution, and reproduction in any

medium, provided the original work is properly cited.
}

in 16 fish species collected from streams and ponds in adjacent areas of Nakdonggang ("gang" means river), several workers investigated the infection status of fishes with DTM in various local areas, especially in southern Provinces, Gyeongsangdo and Jeolla-do [4-10].

Among the digenetic trematodes, fishborne zoonotic trematodes (FZT) provoke a public health problem in some Asian countries. FZT infections including clonorchiasis showed the higher endemicity, and they are important parasitic diseases in some riverside areas of Korea [11-13]. Seo et al. [11] reported high prevalences of clonorchiasis and metagonimiasis among the peoples residing in the riverside areas of Korea. Cho et al. [12] reported the egg positive rates in residents living in 4 large river basins, Nakdonggang, Seomjingang, Yeongsangang, and Geumgang, located in southern parts of Korea. Recently, Kim et al. [13] surveyed the prevalence of clonorchiasis in riparian people along the 5 major rivers of Korea.

On the other hand, the infection status of FZT metacercariae 


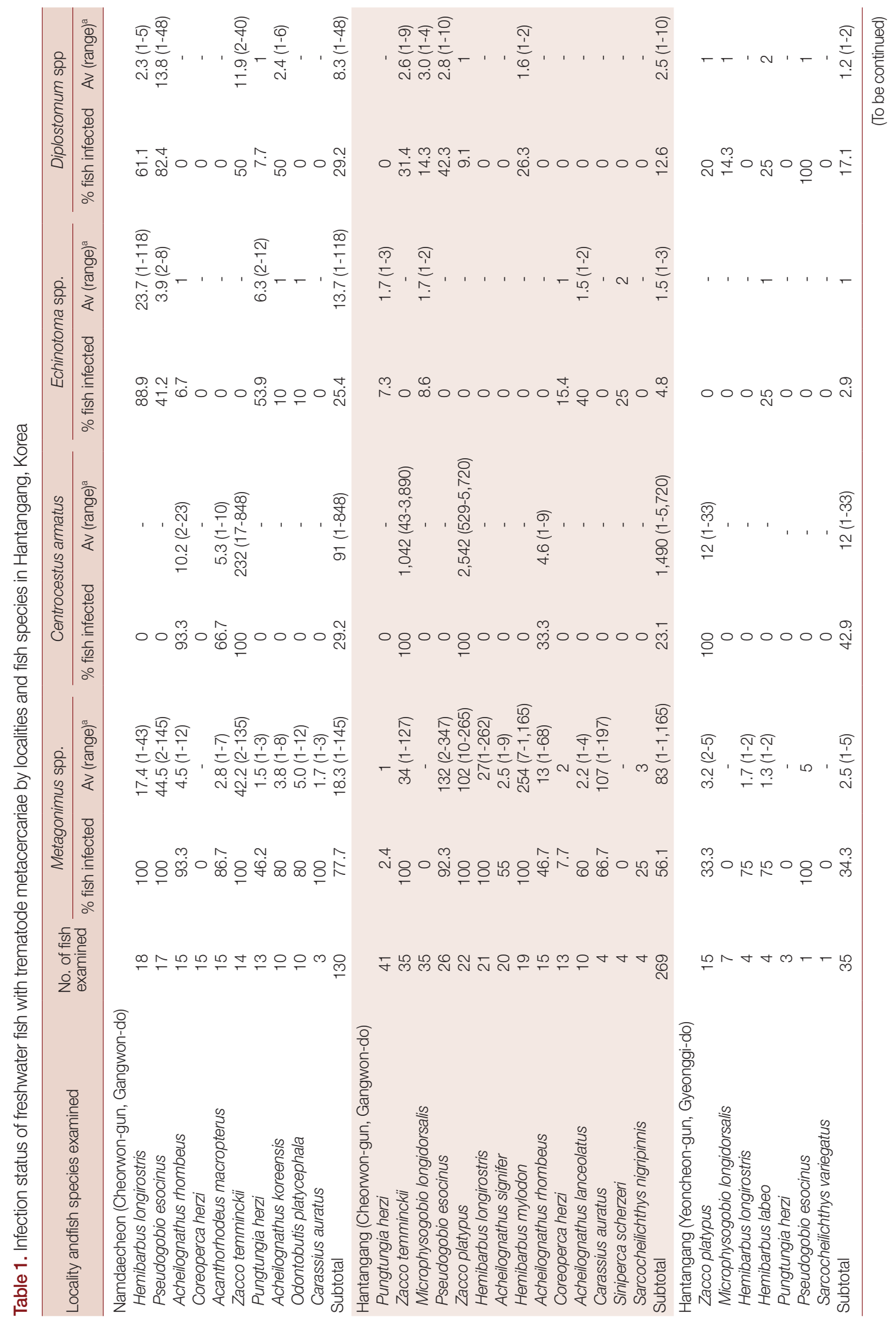




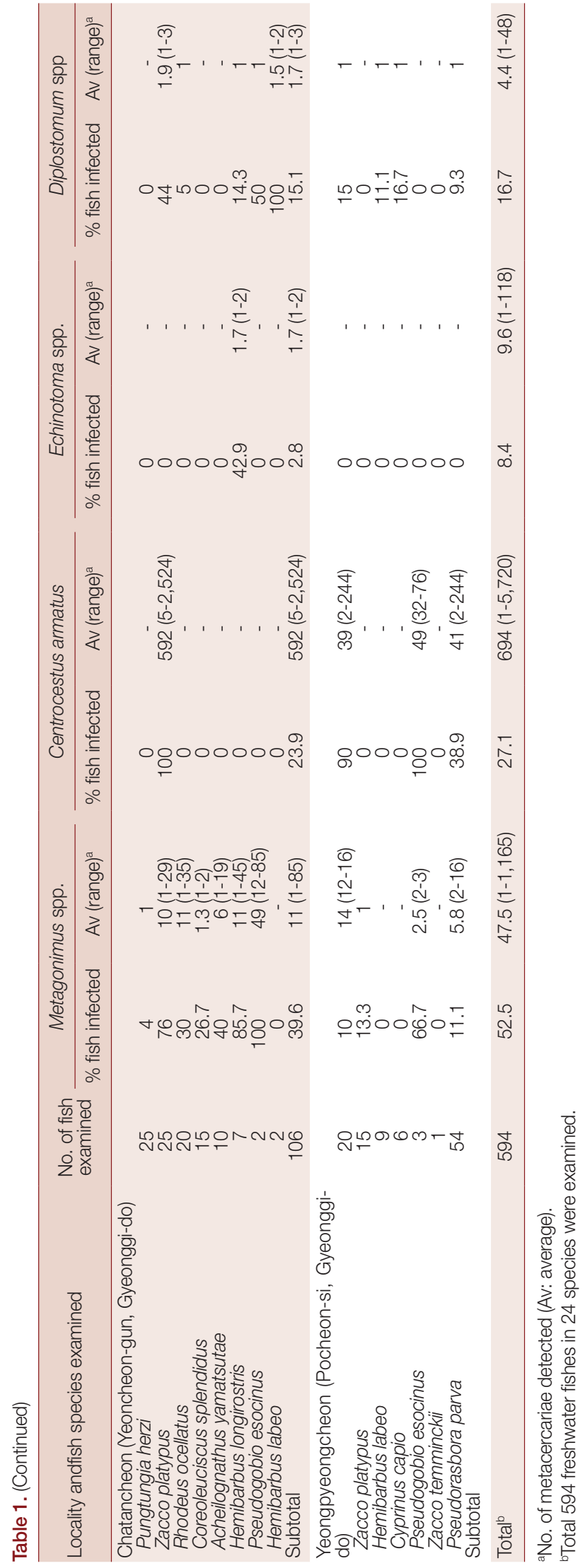

in the second intermediate hosts is used as an important epidemiological index together with those of the infection status with adult worms in the definitive and/or reservoir hosts. Thus, many Korean workers have investigated the infection status of fish from various endemic areas with FZT metacercariae to estimate the endemicities of FZT infections [3-10,14-21]. Most of these studies were performed on specific trematode species, such as Clonorchis sinensis, Metagonimus spp. (including M. yokogawai), Centrocestus armatus, and Echinostoma hortense, and on the fish hosts from specific regions, such as the riverside areas of major rivers in Korea [14-21]. However, with regard to the infection status of DTM, most studies were performed before 2000, and have not been widely conducted in freshwater fish from the water systems of Hantangang and Imjingang. Therefore, we performed the present study to investigate the infection status of freshwater fish with DTM in the water systems of Hantangang and Imjingang in Korea.

\section{MATERIALS AND METHODS}

\section{Freshwater fishes examined by collection sites}

We collected a total of 594 freshwater fishes (in 24 species) in 5 local sites of Hantangang, i.e., Namdaecheon ("cheon" means stream) (latitude: 38.43268 ; longitude: 127.4375) in Cheorwon-gun, Hantangang $(38.23047 ; 127.2179)$ in Cheorwon-gun, Gangwon-do, Hantangang $(37.94375 ; 127.07142)$ in Yeoncheon-gun, Chatancheon $(38.0855 ; 127.07264)$ in Yeoncheon-gun, and Yeongpyeongcheon (38.01408; 127.2088) in Pocheon-si, Gyeonggi-do, from August to October 2013 and in June and August, 2014 (in Namdaecheon and Hantangang in Cheorwon-gun). The numbers and species of fish examined are presented in Table 1. In addition, a total of 283 freshwater fishes (in 15 species) were collected in 3 sites of Imjingang, i.e., Imjingang $(38.04905 ; 127.02154)$ in Yeoncheon-gun, Seokjangcheon $(37.94185 ; 126.93864)$ in Yeoncheon-gun, and Munsancheon $(37.80837 ; 126.85643)$ in Paju-si, Gyeonggi-do, from August to October, 2013. The numbers and species of fish examined are shown in Table 2.

\section{Examination methods}

All collected fishes were transferred with ice to the Department of Parasitology and Tropical Medicine, Gyeongsang National University School of Medicine, Jinju, Korea. After species identification, the fish were ground individually with a mortar with pestle or a grinder. The meat of each ground fish 


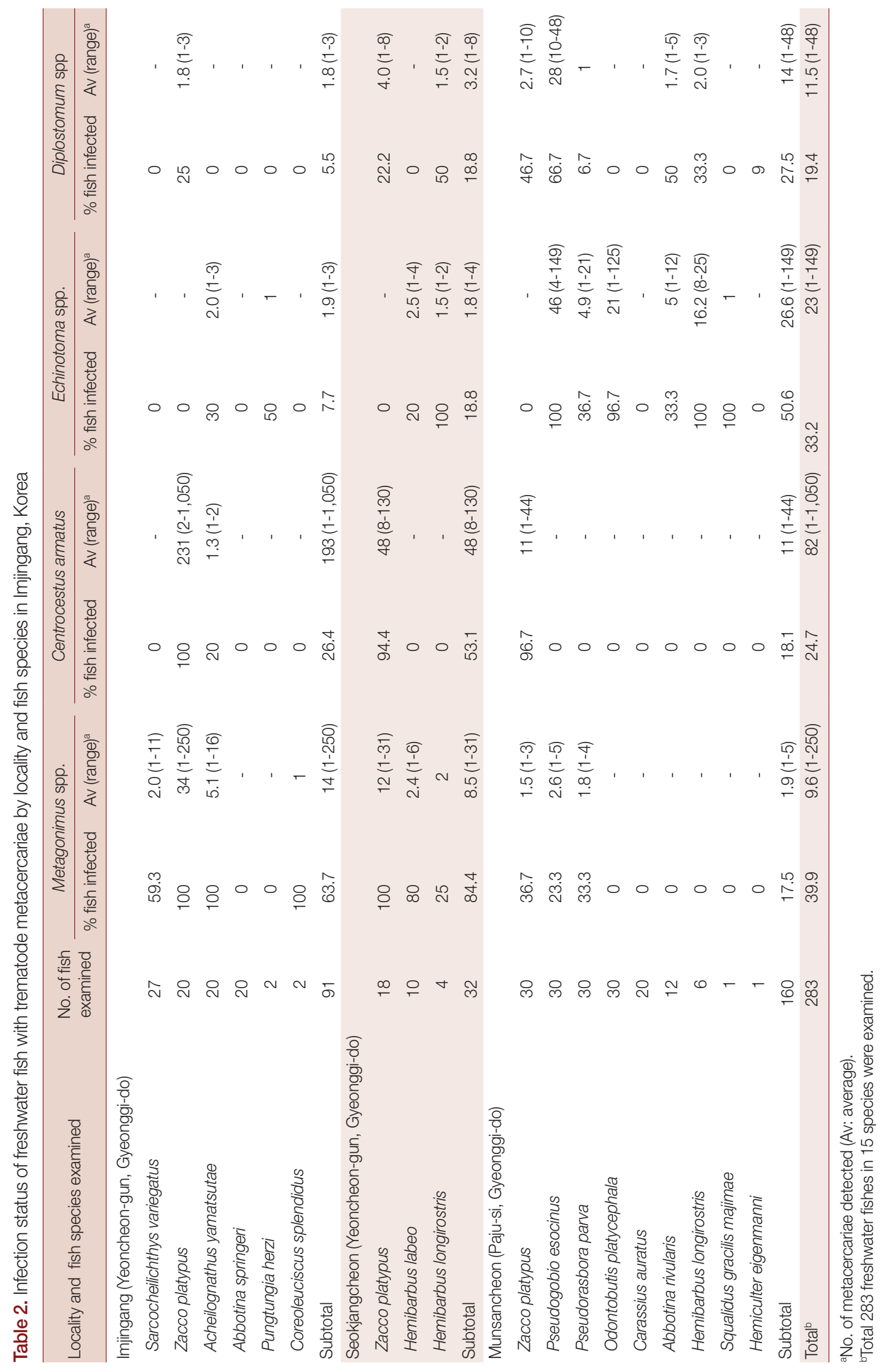


was mixed with artificial gastric juice, and the mixture was incubated at $36^{\circ} \mathrm{C}$ for $2 \mathrm{hr}$. The digested material was filtered with $1 \times 1 \mathrm{~mm}$ of mesh, and washed with $0.85 \%$ saline until the supernatant became clear. The sediment was carefully examined using a stereomicroscope. Each species of digenetic trematode metacercariae were separately collected by the general morphologic features $[1,2]$, and they were counted to get the infection rates and densities by fish species.

\section{RESULTS}

\section{Metagonimus spp. metacercariae}

The metacercariae of Metagonimus spp. were detected in 312 (61.1\%) out of 511 fishes (in 19 spp.) from the water systems of Hantangang, and their average number was 47.5 per fish infected. Their infection status by the fish species and fish collection sites are revealed in Table 1. Metagonimus spp. metacercariae were found in total 113 (59.0\%) out of 191 fishes (in 8 spp.) from the water systems of Imjingang, and their average number was 9.6 per fish infected. Their infection status by the fish species and surveyed areas are shown in Table 2.

\section{Centrocestus armatus metacercariae}

The metacercariae of C. armatus were detected in 161 (75.0\%) out of 179 fishes (in 4 spp.) from the water systems of Hantangang, and their average number was 694 per fish infected. Among the positive fish species, especially 2 species of chubs, Zacco platypus and Zacco temminckii from Hantangang in Cheorwon-gun and Z. platypus from Chatancheon in Yeoncheon-gun were heavily infected with $C$. armatus metacercariae. Their infection status by the fish species and fish collection sites are shown in Table 1. C. armatus metacercariae were found in $70(79.6 \%)$ out of 88 fishes (in 2 spp.) from the water systems of Imjingang, and their average number was 82 per fish infected. The infection status of each fish species with $C$. armatus metacercariae and surveyed areas are presented in Table 2 .

\section{Echinostoma spp. metacercariae}

Echinostoma spp. metacercariae were detected in 50 (25.4\%) out of 197 fishes (in $11 \mathrm{spp}$.) from the water systems of Hantangang, and their average number was 9.6 per fish infected. They were also found in 94 (64.8\%) out of 145 fishes (in 9 spp.) from 3 surveyed sites of Imjingang, and their average density was 23.1 per fish infected. Especially in Munsancheon,
6 fish species were infected with the metacercariae, and their average number was 26.6 per fish infected. The infection status by fish species and surveyed areas are depicted in Tables 1 and 2. To obtain the adult fluke, the echinostome metacercariae collected in 3 fish species (Odontobutis platycephala, Pseudogobio esocinus, and Hemibarbus longirostris) from Munsancheon were orally infected to albino rats. Adult flukes of Echinostoma hortense were recovered only in the small intestines of rats infected with the metacercariae from $O$. platycephala. The echinostome metacercariae from P. esocinus and $H$. longirostris were morphologically identical with those of $E$. hortense from $O$. platycephala, but seemed less viable. The metacercariae of $E$. hortense were elliptical and 145-175 (156)×95-120 (108) $\mu \mathrm{m}$ in size, had 2 suckers, a head crown with 27 collar spines including 4 corner spines in each end, 2 rows of excretory granules (Fig. 1).

\section{Diplostomum spp. mesocercariae}

Diplostomum spp. mesocercariae (=diplostomula) were detected in fishes from all surveyed areas in water systems of Hantangang and Imjingang. Their infection status by the fish species and surveyed areas are shown in Tables 1 and 2.

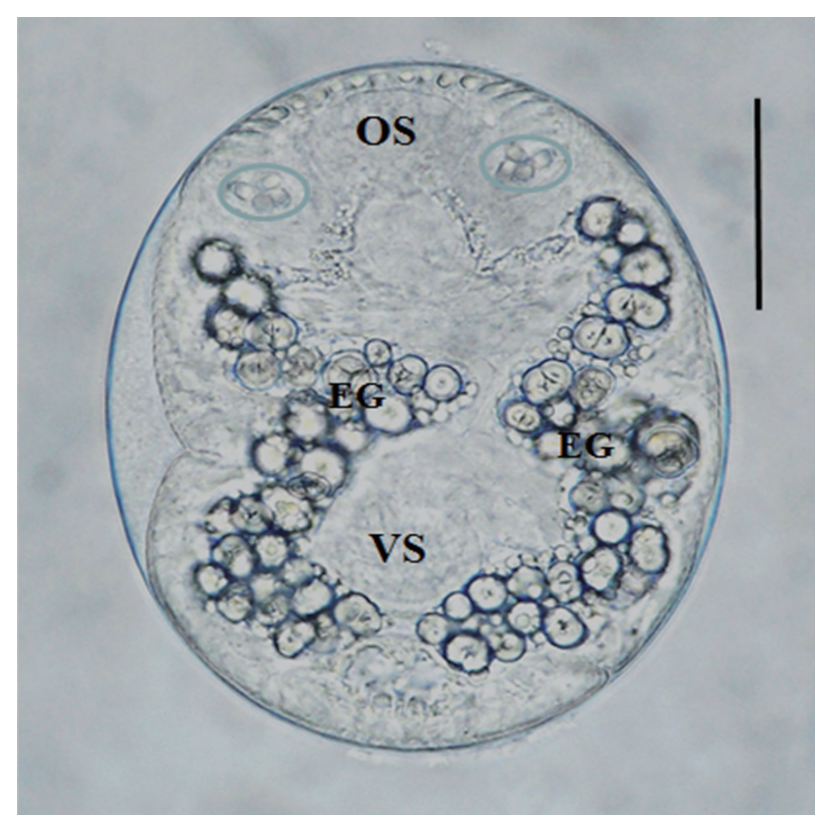

Fig. 1. A metacercaria of Echinostoma hortense found in Odontobutis platycephala in Munsancheon, Paju-si, Gyeonggi-do, which is elliptical and $156 \times 108 \mu \mathrm{m}$ in average size, has 2 suckers, a head crown with 27 collar spines including 4 corner ones (encircled) in each end, and 2 rows of excretory granules (EG). 
Table 3. Infection status of Clonorchis sinensis metacercariae in fishes from Hantangang and Munsancheon in Korea

\begin{tabular}{|c|c|c|c|c|c|}
\hline \multirow{2}{*}{ Locality and fish species examined } & \multirow{2}{*}{$\begin{array}{l}\text { No. of fish } \\
\text { examined }\end{array}$} & \multirow{2}{*}{$\begin{array}{l}\text { No. (\%)of fish } \\
\text { infected }\end{array}$} & \multicolumn{3}{|c|}{ No. of metacercariae detected } \\
\hline & & & Total & Range & Average \\
\hline \multicolumn{6}{|c|}{ Hantangang (Cheorwon-gun, Gangwon-do) } \\
\hline Pungtungia herzi & 41 & $5(12.2)$ & 10 & $1-3$ & 2 \\
\hline Microphysogobio longidorsalis & 35 & $1(2.9)$ & 2 & - & 2 \\
\hline Hemibarbus mylodon & 19 & 1 (5.3) & 1 & - & 1 \\
\hline Subtotal & 95 & $7(7.4)$ & 13 & $1-3$ & 1.9 \\
\hline \multicolumn{6}{|l|}{ Munsancheon (Paju-si, Gyeonggi-do) } \\
\hline Pseudorasbora parva & 30 & $24(85.3)$ & 1,269 & $1-1,012$ & 52.9 \\
\hline Pseudogobio esocinus & 30 & $2(6.7)$ & 17 & $1-16$ & 8.5 \\
\hline Carassius auratus & 20 & $1(5.0)$ & 1 & - & 1 \\
\hline Abbotina revulais & 12 & $10(83.3)$ & 84 & $1-22$ & 8.4 \\
\hline Hemibarbus longirostris & 6 & $1(16.7)$ & 2 & - & 2 \\
\hline Hemiculter eigenmanni & 1 & $1(100)$ & 46 & - & 46 \\
\hline Squalidus gracilis majimae & 1 & $1(100)$ & 4 & - & 4 \\
\hline Subtotal & 100 & $40(40.0)$ & 1,423 & $1-1,012$ & 35.6 \\
\hline Total & 195 & $47(24.1)$ & 1,436 & $1-1,012$ & 30.6 \\
\hline
\end{tabular}

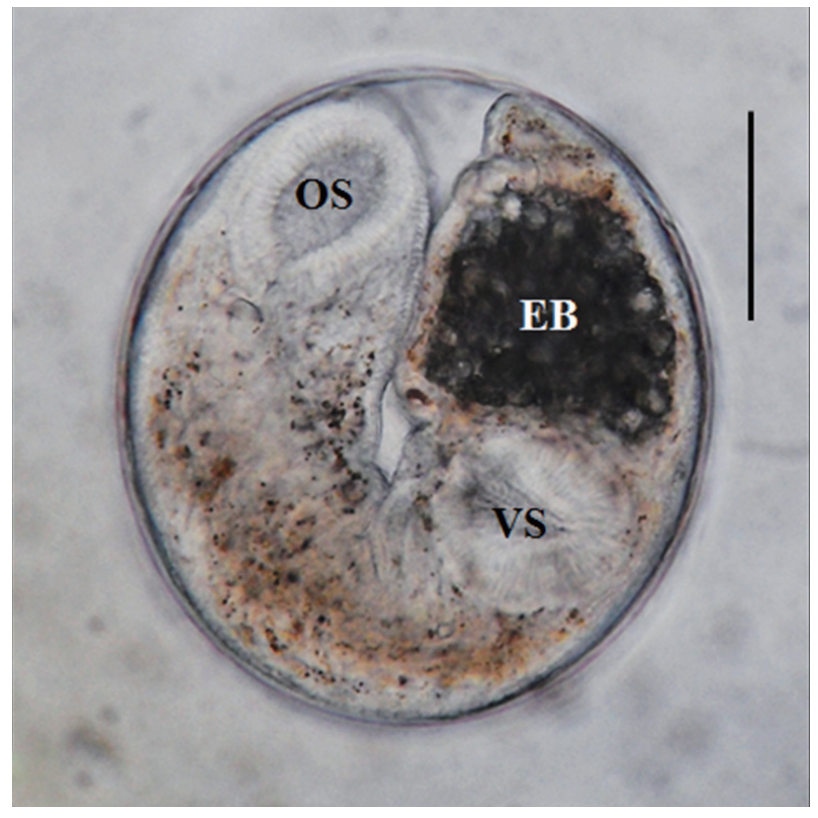

Fig. 2. A metacercaria of Clonorchis sinensis collected from Pseudorasbora parva in Munsancheon, Paju-si, Gyeonggi-do, which is elliptical and $158 \times 138 \mu \mathrm{m}$ in average size, has nearlyequal sized 2 suckers (OS: oral \& VS: ventral sucker), brownish pigment granules and an O-shaped excretory bladder (EB).

\section{Clonorchis sinensis metacercariae}

The metacercariae of C. sinensis were detected in 7 (7.4\%) out of 95 fishes in 3 species (Pungtungia herzi, Microphysogobio longidorsalis, and Hemibarbus mylodon), from Hantangang in Cheorwon-gun, Gangwon-do, and their average density was 1.9 per fish infected. They were also found in 40 (40.0\%) fishes in 7 species from Munsancheon, and their average density

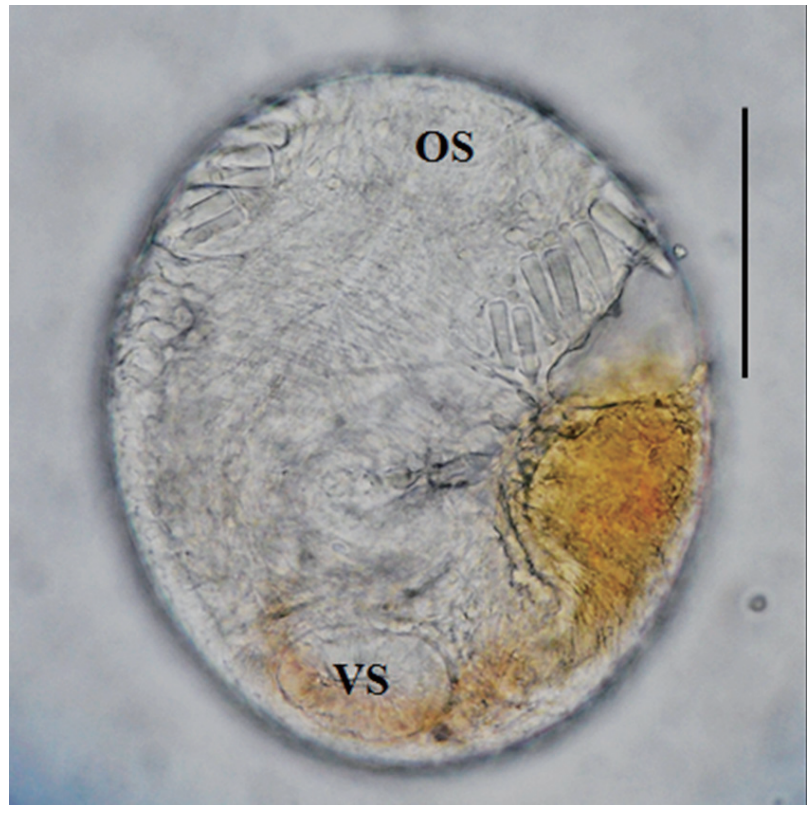

Fig. 3. A metacercaria of Stephanoprora sp. detected in Z. platypus from Seokjangcheon in Yeoncheon-gun, Gyeonggi-do, which is elliptical, $128 \times 98 \mu \mathrm{m}$ in average size, has 22 color spines interrupted in the dorso-median of oral sucker, minute excretory granules and yellowish pigment. Scale bar is $50 \mu \mathrm{m}$.

was 35.6 per fish infected. The infection status by the fish species and the locality are designated in Table 3 . The metacercariae of C. sinensis collected from Pseudorasbora parva in Munsancheon were elliptical and 143-170 (158)×123-155 (138) $\mu \mathrm{m}$ in size, had 2 nearly equal-sized suckers, brownish pigment granules, and an O-shaped excretory bladder (Fig. 2). 
Table 4. Infection status of Stephanoprora spp. metacercariae in fishes from the water systems of Hantangang and Imjingang in Korea

\begin{tabular}{|c|c|c|c|c|c|}
\hline \multirow{2}{*}{ Locality and fish species examined } & \multirow{2}{*}{$\begin{array}{l}\text { No. of fish } \\
\text { examined }\end{array}$} & \multirow{2}{*}{$\begin{array}{l}\text { No. (\%) of fish } \\
\text { infected }\end{array}$} & \multicolumn{3}{|c|}{ No. of metacercariae detected } \\
\hline & & & Total & Range & Average \\
\hline \multicolumn{6}{|c|}{ Chatancheon (Yeoncheon-gun, Gyeonggi-do) } \\
\hline Zacco platypus & 25 & $1(4.0)$ & 1 & - & 1 \\
\hline \multicolumn{6}{|c|}{ Imjingang (Yeoncheon-gun, Gyeonggi-do) } \\
\hline Zacco platypus & 20 & $3(15.0)$ & 7 & $1-3$ & 2.3 \\
\hline Acheilognathus yamatsutae & 20 & $1(5.0)$ & 1 & - & 1 \\
\hline Subtotal & 40 & $4(10.0)$ & 8 & $1-3$ & 2 \\
\hline \multicolumn{6}{|c|}{ Seokjangcheon (Yeoncheon-gun, Gyeonggi-do) } \\
\hline Zacco platypus & 18 & $6(33.3)$ & 33 & $1-12$ & 5.5 \\
\hline Total & 83 & $11(13.3)$ & 42 & $1-12$ & 3.8 \\
\hline
\end{tabular}

\section{Stephanoprora spp. metacercariae}

Stephanoprora spp. metacercariae were detected in 2 fish species, i.e., Z. platypus and Acheilognathus yamatsutae, from 3 surveyed areas. Their infection status by the fish species and surveyed areas are shown in Table 4. They were elliptical in shape, 123-138 (128) ×90-110 (98) $\mu \mathrm{m}$ in size, had 22 color spines interrupted in dorsomedially, minute excretory granules, and yellowish pigment (Fig. 3).

\section{Other trematode metacercariae}

Clinostomum complanatum metacercariae were found in 2 fish species, $P$. herzi (in only 1 of 25 fish examined) and $H$. longirostris (in 2 of 7 fish: 28.6\%), from Chatancheon, and their number was 1.0 per fish infected respectively. Metorchis orientalis metacercariae were detected in 3 fish species, P. parva (in 4 of 30 fish examined: 13.3\%), P. esocinus (in 1 of 30 fish) and Abbotina rivularis (in 8 of 12 fish: 66.7\%), from Munsancheon, and their numbers per fish infected were 3.5, 1.0, and 2.5 respectively. Metorchis taiwanensis metacercariae were found in 2 fish species, $P$. parva (in 3 of 30 fish examined) and $O$. platycephala (in 2 of 30 fish: 6.7\%), from Munsancheon, and their average numbers were 1.0 and 1.5 per fish infected, respectively.

\section{DISCUSSION}

Kim et al. [14] reported that all fishes from upper regions of Cheongju-si, Chungcheongbuk-do were negative for $C$. sinensis metacercariae. However, Cho et al. [15] detected C. sinensis metacercariae in 2 fish species, Pungtungia herzi and Squalidus japonicus coreanus, only from Hantangang in Cheorwon-gun, among 9 localities surveyed in Gangwon-do. Cho et al. [22] also found them in 4 fish species, i.e., P. herzi, S. japonicus coreanus, Acheilognathus rhombeus, and Ladislabia taczanowskii, from Hantangang in Cheorwon-gun. In the present study, we also detected $C$. sinensis metacercariae in 3 fish species, i.e., $P$. herzi, Microphysogobio longidorsalis, and Hemibarbus mylodon, from Hantangang in Cheorwon-gun, Gangwon-do, although their densities were very low. Therefore, it is confirmed again that the life cycle of $C$. sinensis is still maintained in some limited areas of Hantangang in Cheorwon-gun, Gangwon-do.

In addition, we also found $C$. sinensis metacercariae in 7 fish species from Munsancheon in Paju-si, Gyeonggi-do. This finding is the first on the presence of $C$. sinensis metacercariae in fish from the water systems of Imjingang. Therefore, it is interesting and important in epidemiological aspects of clonorchiasis. Further intensive studies on the snail and other fish intermediate hosts, humans, and reservoir definitive hosts should be investigated in the near future in the water systems of Imjingang.

A successful fish collection is a prerequisite in epidemiological surveys of FZT metacercarial infections like the present study. However, we failed to do it in some surveyed areas such as Hantangang in Yeoncheon-gun, Yeongpyeongcheon, and Seokjangcheon. In these 3 areas, the water current was so rapid and turbulent, the fish collection was possible only by the casting net at the daytime. Whereas in case of Hantangang in Cheorwon-gun, and Munsancheon, 2 fish catching methods, i.e., netting and casting net, were used together to collect various species of fish. Especially, the netting was a recommendable method for the collection of nocturnal fish species.

In the Republic of Korea, Chun [3] described more than 11 species of DTM, i.e., C. sinensis, Metorchis orientalis, Exorchis oviformis, Pseudexorchis major, Echinochasmus japonicus, E. perfoliatus, Cyathocotyle orientalis, C. armatus, Metacercaria hasegawai, Rhypidocotyle lingualis, Diplostomum sp., and unidentified spe- 
cies, in 16 fish species from streams and ponds in adjacent areas of Nakdonggang. Lee [4] reported more than 10 species of DTM found in 12 fish species from Geumhogang, a branch of Nakdonggang, in Daegu Metropolitan City. Rhee et al. [6,7] detected more than 13 species of DTM, i.e., C. sinensis, M. orientalis, M. taiwanensis, Metagonimus spp., E. oviformis, P. major, E. japonicus, E. hortense, C. orientalis, Holostephanus nipponicus, $C$. armatus, Metacercaria hasegawai, and Diplostomum orientale, in 32 and 33 fish species from Mangyeonggang and Dongjingang in Jeollabuk-do. Besides, several studies were performed on the infection status of DTM in freshwater fishes along the riverside areas of Gyeongsang-do [5,8-10]. In the present study, we investigated the infection status of 9 DTM, i.e., C. sinensis, Metagonimus spp., C. armatus, Echinostoma spp., Diplostomum sp., Stephanoprora sp., M. orientalis, M. taiwanensis, and C. complanatum, and did not detect 5 species, i.e., Metacercaria hasegawai, E. oviformis, P. major, C. orientalis, and H. nipponicum, among the list of DTM described previously. The present study is meaningful as the first trial on the investigation of DTM infections in fishes from the northern regions of the Korean peninsula, although some studies on FZT metacercariae infections were conducted in fishes from Hantangang in Cheorwon-gun, Gangwon-do [15,22].

Stephanoprora sp. is newly added among the list of DTM in Korea. This genus, Stephanoprora, is a group of the Family Echinostomatidae, and mainly found from birds and rarely from mammals. Chai et al. [23] already described Stephanoprora sp. adult recovered in the small intestine of a stray cat from a local market of Busan Metropolitan City. They tentatively called it Stephanoprora sp., but they mentioned that it should be considered identical with $S$. denticulata although there are minor differences in some morphological features. We were unable to obtain the adult worms from an experimental infection of animals with Stephanoprora sp. metacercariae. However, in faunistic points of view, we should continuously pay attention to this interesting 22-collar-spined echinostome in Korea.

Among 9 species of DTM subjected in this study, Metagonimus spp. were the most highly prevalent, detected in 425 (48.5\%) out of 877 fishes examined, and their prevalence was $60.5 \%$ among the positive fish species group, total 702 fish. However, their metacercarial burdens were relatively low. The burden of Metagonimus spp. was the highest in fishes from Hantangang in Cheorwon-gun, more than 80 (average), and it was less than 20 in fishes from remaining 7 localities. Unlike Cho et al. [22], the susceptible fish species, i.e., Plecoglossus al- tivelis and Tribolodon hakonensis, were not examined in this study. On the other hand, at least 64 fish species (in 42 genera) were reported as the second intermediate host of Metagonimus spp. in Korea $[1,22]$. In the present study, Metagonimus spp. metacercariae were found in 21 fish species from the water systems of Hantangang and Imjingang. All fish species except for Acheilognathus koreensis were already listed among the fish intermediate hosts of Metagonimus spp. previously in Korea $[1,22]$.

A total of 24 fish species in 20 genera were previously listed as the second intermediate hosts of $C$. armatus in Korea $[1,21,22]$. In this study, the metacercariae of $C$. armatus were detected in 5 fish species, Z. platypus, Z. temminckii, A. rhombeus, A. yamatsutae, and A. macropterus from the water systems of Hantangang and Imjingang. Especially, 2 species of chubs, $Z$. platypus and $Z$. temminckii from Hantangang in Cheorwon-gun were highly and heavily infected. These findings agreed well with Cho et al. [22]. The high prevalence and heavy metacercarial burden in 2 species of chubs were found in almost all regions of Ganwon-do surveyed. In addition, 2 species of bitterlings, i.e., A. yamatsutae and A. macropterus, were first confirmed as the fish hosts of $C$. armatus in this study. Accordingly, total 26 fish species in 21 genera are included among the second intermediate hosts of $C$. armatus in Korea.

In the present study, Echinostoma spp. metacercariae were detected in 15 fish species, but their species names could not be determined. Although 3 species, i.e., Echinostoma cinetorchis, E. hortense, and Echinostoma revolutum, have been known to exist in Korea, there are possibilities for distribution of other Echinostoma spp. infecting birds and mammals via fish intermediate hosts. Among the 3 echinostome species, E. hortense is the dominant zoonotic species, and 8 fish species, i.e., Misgurnus anguillicaudatus, Misgurnus mizolepis, R. oxycephalus, Odontobutis interrupta, S. japonicus coreanus, Rhinogobius brunneus, A. macropterus, and Acanthogobius flavimanus, have been reported as the second intermediate hosts in Korea $[1,19,22]$. On the other hand, some fish species, i.e., O. platycephala, P. esocinus, and $H$. longirostris, from Munsancheon were highly infected with Echinostoma spp. metacercariae. In the adult worm recovery experiment, E. hortense adult flukes were harvested in the small intestines of experimentally infected rats.

Diplostomula are the metacercariae (mesocercariae) of Diplostoma spp. (Digenea: Diplostomidae) and lodge in fish and amphibians. Adult worms infect mainly birds and rarely in mammals. In the present study, diplostomula were detected in 
fishes from all surveyed areas. Total 13 fish species, i.e., A. rivulairs, A. koreensis, C. capio, H. longirostris, H. labeo, H. mylodon, M. longidorsalis, P. esocinus, P. parva, P. herzi, R. ocellatus, Z. platypus, and $Z$. temminckii, are listed among the second intermediate hosts of unknown Diplostoma spp. in Korea. Among these fish hosts, P. esocinus from Namdaecheon and Munsancheon were most highly and heavily infected. Rhee et al. [7] detected diplostomula in a loach, Misgurnus anguillicaudatus, from Dongjingang in Jeollabuk-do, and named them as Diplostoma orientale. However, they did not try to recover the adult flukes, and identified them with mesocercariae only. If it is so, what species of Diplostoma are distributed in Korea? The species determination of Diplostoma mesocercariae infected in fish hosts is one of the taxonomic problems to be solved with recovery of the adult flukes in Korea.

Conclusively, it is confirmed for the first time in Korea that a variety of trematode species are inhabited in fishes from the water systems of Hantangang and Imjingang, in northern parts of South Korea. In epidemiological aspects of FZT infections, these 2 regions are endemic areas of intestinal flukes, i.e., Metagonimus spp., C. armatus, and Echinostoma spp., rather than $C$. sinensis.

\section{ACKNOWLEDGMENTS}

This study was supported by a grant from Korea Association of Health Promotion (2013). We thank Jung-A Kim and HeeJoo Kim, Department of Parasitology and Tropical Medicine, Gyeongsang National University School of Medicine, Jinju, Korea, for their help in examination of fish.

\section{CONFLICT OF INTEREST}

The authors have no conflicts of interest concerning the work reported in this paper.

\section{REFERENCES}

1. Sohn WM. Fish-borne zoonotic trematode metacercariae in the Republic of Korea. Korean J Parasitol 2009; 47 (suppl): S103S113.

2. Sohn WM. Invertebrate Founa of Korea Vol. 6, No. 1. Trematodes. Incheon, Korea. The National Institute of Biological Resources. 2013. pp 1-125.

3. Chun SK. Studies on some trematodes whose intermediate hosts are fishes in the Naktong river. Bull Fish Coll 1962; 4: 21-38 (in
Korean).

4. Lee JT. Studies on the metacercariae from freshwater fishes in the Kum-Ho River. Korean J Parasitol 1968; 6: 77-99.

5. Hwang JT, Choi DW. Changing pattern of infestation with larval trematodes from freshwater fish in river Kumho, Kyungpook Province, Korea. Kyungpook Univ Med J 1980; 21: 460-475.

6. Rhee JK, Lee HI, Baek BK, Kim PG. Survey on encysted cercariae of trematodes from freshwater fishes in Mangyeong riverside area. Korean J Parasitol 1983; 21: 187-192.

7. Rhee JK, Rim MH, Baek BK, Lee HI. Survey on encysted cercariae of trematodes from freshwater fishes in Tongjin riverside areas in Korea. Korean J Parasitol 1984; 22: 190-202.

8. Joo CY. Changing pattern of infection with digenetic larval trematodes from freshwater fish in river Taewha, Kyongnam Province. Korean J Parasitol 1988; 26: 263-274.

9. Kong HH, Choi BR, Moon HC, Choi DW. Larval digenetic trematodes from freshwater fish in river Miryang, Korea. Jpn J Parasitol 1995; 44: 112-118.

10. Sohn WM, Choi YS. Infection status with trematode metacercariae in the freshwater fish from Chunamchosuchi (pond), Uichang-gun, Kyongsangnam-do, Korea. Korean J Parasitol 1997; 35: 165-170.

11. Seo BS, Lee SH, Cho SY, Chai JY, Hong ST, Han IS, Sohn JS, Cho BH, Ahn SR, Lee SK, Chung SC, Kang KS, Shim HS, Hwang IS. An epidemiologic study on clonorchiasis and metagonimiasis in riverside areas in Korea. Korean J Parasitol 1981; 19: 137-150.

12. Cho SH, Lee KY, Lee BC, Cho PY, Cheun HI, Hong ST, Sohn WM, Kim TS. Prevalence of clonorchiasis in southern endemic areas of Korea in 2006. Korean J Parasitol 2008; 46: 133-137.

13. Kim HK, Cheun HI, Chung BS, Lee KY, Kim TS, Lee SE, Lee WJ, Cho SH. Prevalence of Clonorchis sinensis infections along the five major rivers in Republic of Korea, 2007. Public Health Res Perspect 2010; 1: 43-49.

14. Kim EM, Kim JL, Choi SY, Kim JW, Kim S, Choi MH, Bae YM, Lee SH, Hong ST. Infection status of freshwater fish with metacercariae of Clonorchis sinensis in Korea. Korean J Paraitol 2008; 46: 247-251.

15. Cho SH, Sohn WM, Na BK, Kim TS, Kong Y, Eom KS, Seok WS, Lee T. Prevalence of Clonorchis sinensis metacercariae in freshwater fish from three latitudinal regions of the Korean peninsula. Korean J Parasitol 2011; 49: 385-398.

16. Seo BS, Hong ST, Chai JY, Lee SH. Study on Metagonimus yokogawai (Katsurada, 1912) in Korea. VI. The geographical distribution of metacercarial infection in sweetfish along the east and south coast. Korean J Parasitol 1982; 20: 28-32 (in Korean).

17. Song CY, Lee SH, Jeon SR. Studies on the intestinal fluke, Metagonimus yokogawai Katsurada, 1912 in Korea. IV. Geographical distribution of sweetfish and infection status with Metagonimus metacercariae in south-eastern area of Korea. Korean J Parasitol 1985; 23: 123-138 (in Korean).

18. Cho SH, Kim TS, Na BK, Sohn WM. Prevalence of Metagonimus metacercariae in sweetfish, Plecoglossus altivelis, from eastern and southern coastal areas in Korea. Korean J Parasitol 2011; 49: 161- 
165.

19. Ryang YS, Ahn YK, Lee KW, Kim TS, Hhan MH. Two cases of natural human infection by Echinostoma hortense and its second intermediate host in Wonju area. Korean J Parasitol 1985; 23: 33-40 (in Korean).

20. Kim DG, Kim TS, Cho SH, Song HJ, Sohn WM. Heterophyid metacercarial infections in brackish water fishes from Jinju-man (Bay), Kyongsangnam-do, Korea. Korean J Parasitol 2006; 44: 7-13.

21. Hong SJ, Woo HC, Kim IT. Study on Centrocestus armatus in Ko- rea. I. Infection status of Zacco platypus and Z. temminckii with the metacercariae of C. armatus. Korean J Parasitol 1989; 27: 4146 (in Korean).

22. Cho SH, Lee WJ, Kim TS, Seok WS, Lee TJ, Jeong KJ, Na BK, Sohn WM. Prevalence of zoonotic trematode metacercariae in freshwater fish from Gangwon-do, Korea. Korean J Parasitol 2014; 52: 399-412.

23. Chai JY, Bahk YY, Sohn WM. Trematodes recovered in the small intestine of stray cats in the Republic of Korea. Korean J Parasitol 2013; 51: 99-106. 